\title{
The strength of interconnectedness between structure and culture: market development in the presence of over- embedded social structure in the lime market of Hui Town
}

\author{
Ping Fu
}

\section{Correspondence:}

pfu@mail.ccnu.edu.cn

College of Sociology, Central China

Normal University, 152 Luoyu Road,

Wuhan City, Hubei Province 430079,

People's Republic of China

\begin{abstract}
This article brings together two different approaches in the new economic sociology — structural embeddedness and cultural embeddedness - to understand the transformation and development of a market. Markets are considered over-embedded in social structure and assessed to be in decline when their economic transactions are dependent on secondary clientelism, in which the reseller serves as patron and the supplier as client. Based on ethnographic data from the lime market in Hui Town, this study examines how this kind of market develops in the presence of transactions embedded in secondary clientelism. From the perspective of the interconnected mode between structure and culture, these findings demonstrate that the coupling induction from secondary clientelist networks and new business ideology is the underlying mechanism allowing market development. This means that the process of marketization might not necessarily be associated with market transactions' depersonalization or social disembedding, and instead development may be hindered if the market is devoid of social bonds and social virtue.
\end{abstract}

Keywords: Market development, Interconnected mode between structure and culture, Over-embedded social structure, Secondary clientelism

According to Weber, an important prerequisite for modern or rational capitalism is that the market should be "free", i.e., market transactions should face no unreasonable restrictions and be separate from personal relationships (Weber, 2006a[1927], 2006b[1925]). Thus, formal rationality is one of the intrinsic characteristics of any market transaction. Indeed, there is no place for personal relationships or authoritative structures in ideal market models or in classical market theories. In neoclassical economics, the social relationship is regarded as a friction coefficient, and the hypothesis of autonomous actors precludes the analysis of social relationships. As for the new institutional economics, clearly defined property rights and sufficiently low transaction costs seem to be prerequisites for market transactions and the realization of economic efficiency. In this sense, interventions from political sources or authorities will hinder market development, since they can blur the boundaries of property rights. Personal

(c) 2016 The Author(s). Open Access This article is distributed under the terms of the Creative Commons Attribution 4.0 International License (http://creativecommons.org/licenses/by/4.0/), which permits unrestricted use, distribution, and reproduction in any medium, provided you give appropriate credit to the original author(s) and the source, provide a link to the Creative Commons license, and indicate if changes were made. 
relationships also blue these boundaries, as they are redundant in market exchange and increase transaction costs. Therefore, it is a theoretical prerequisite for market development that market exchange be separated from various types of personal relationships and authority structures. However, ongoing market development and economic growth in China since 1978 have challenged this dominant view. As argued by Whyte (2009), China's stunning economic performance since 1978 has not only been unexpected but contradicts much received wisdom in the study of development. One significant paradox lies in the fact that instead of fading away as the market grows, personal relationships and authority structures continue to play indispensable roles in economic exchange and market development. In short, China has made great economic achievements while most of its markets are enmeshed in an over-embedded social structure.

The patron-client network can be defined as a particular exchange relationship between two parties with disparate status, ${ }^{1}$ involving both personal relationships and authority structures. Once an economic exchange attaches itself to relationships in such a patron-client network, the market is "unfree" due to the "over-embeddedness" of its social structure. While recent sociological research has supported the idea that the social embeddedness constitutes a key characteristic of modern market institutions and contributes to economic outcomes (Beckert 2002; Abolafia 2005; Fu 2009), the social mechanism through which the exchange relationship based on the patron-client network facilitates market development and stability has been largely ignored. As a critical case that may shed some light on this question, the lime market in Hui Town renders an important opportunity for us to understand and explain some of the myths and the paradoxes that have emerged in China during this period of transformation.

\section{Theoretical backgrounds and frames}

\section{Patron-client networks and market development}

Social relationships occupy such a dominant role in market activities in China that some scholars have concluded that entering into markets in China implies embedding oneself in a gigantic web of social relationships (Su \& Littlefield 2001), and, for the Chinese, nurturing social relationships is fundamental to performing commercial activities (Hamilton 2006). Despite these divergent views on the essence, the wax, and wane of social relationships, scholars concur with the role of social relationships-they not only determine economic performance and the sustainable growth of an enterprise, but also serve as one of the crucial factors strengthening the Chinese economy (Chan 2000; Keister 2001; Gold et al. 2002; Luo 2007). The patron-client network is an important component of the gigantic web of market relationships. In fact, most sociological research focusing on relationships in the market has implicitly touched on the concept of patron-client networks, even though they are not directly intend to examine such network. Many have agreed that the emergence of the patron-client network and its crucial role in market transactions are artifacts of the institutional properties of societies in transition (Odgaard 1992; Zhang 1996).

According to (Oi 1989), prior to market reform, the general public resorts to political patrons, seeking support for private interests due to the limited means at their disposal. After the reform, however, the patron-client relation still remain important in obtaining economic opportunities and has only become increasingly complex, despite the fact 
that economic transactions have become heavily dependent on markets rather than the state. She has further argued that a reliance on political networks and bureaucratic structures is a unique characteristic of the municipal economy and highlights the importance of the patron-client network to economic development (Oi 1999). Similar arguments have also been formulated from perspectives of the interactions between political and economic elites (Shirk 1993; Dickson 2008) and the bond between governments and enterprises ( $\mathrm{Lu}$ and Pan 2009); the general consensus is that the intimate association between political and economic elites (the marriage of power and wealth) has propelled the macro economic growth in China.

For a few scholars who have explicitly studied clientelism in China's commercializing economy (for example, Nee 1992 and Wank 1995), their attention is focused on the form of interactions between bureaucracy and enterprises, as well as its institutional roots. Both Nee (1992) and Wank (1995) concur that the "dependent clientelism" before market reform has evolved into a kind of "symbiotic clientelism" between private businessmen and officials. Though this new type of patronage relationship denies equal access to market competition, the economic organizations and their modes of operation that are shaped by such relations are by no means inefficient. However, Nee argues that the clientelist networks actually result from an under-developed institutional system and thus are expected to fall away as market institutions matured (Nee 1992). In other words, the patron-client relation between the government and enterprises is the product of immature market reform and a low level of marketization. Wank holds an opposing view. In one of his early studies, Wank (1995) argues that, from the perspective of local governments, the powerful state institution and characteristics of its operational mechanisms provide conditions for the creation of an alliance between local officials and entrepreneurs, while shrinking incomes and increasing uncertainties in the market reform process provide incentives for local officials to engage in such alliance. In a following study, Wank (1996) continues his analysis from the entrepreneur's perspective and concludes that entrepreneurs in China, as a market strategy, nurture ties with local cadres in their pursuit of higher profits, and such bureaucratic ties are referred to as "patrons" (houtai laoban, literally "backstage bosses") and "supporters" (kaoshan). Wank's study indicates that clientelism has been institutionalized into the very nature of the market economy with its own institutional bases for social trust and behavior rationality; such clientelism won't fade away during the marketization process-as clientelism itself has turned into an inherent component of marketization and provides a rationale for market activities (Wank 1996).

However, many scholars do not agree with Wank's conclusion, arguing that the patronclient relation will be replaced by formal institutional structures as marketization proceeds, because it has led to problems of "over-embeddedness" and a transaction structure oriented towards particularism. While these features may be "effective" in the short-term, they are detrimental to economic growth in the long run; similarly, they may be beneficial to stakeholders but can inflict costs on others and on social good (Fan 2002; Li 2003; Lee 2007). In contrast, Wank regards clientelism as a catalyst for China's economic transformation and an endogenous, stable, and constant component of the market economy (Wank 1999).

Despite the fact that China has experienced great transformations since the market reform, the depoliticalization of the economic realm does not necessarily equate to a departure or shrinkage of political power under transitional institutional settings. In 
order to secure profits, seize better economic opportunities, and obtain more competitive advantages, private enterprises not only have incentives to but also invest real efforts in constructing patron-client relations.

\section{From primary clientelism to secondary clientelism}

Though clientelism focuses on the networks of social actors, it entails macro factors such as the power structure of particular societies, the flow of resources, modes of economic operations, and even cultural traditions. As a meso-level theoretical framework, its popularity relies on the ability of its analytical logics to dissolve distinctions between the state, markets, and society, thus paving the way for a problem-centered and multifactorial analysis. However, the mere focus on the patron-client relation between bureaucracies and enterprises may overlook some equally important phenomena.

Current studies on clientelism assume that the two parties involved are not relationally separate from each other; namely, they can interact face-to-face through various channels and have mutual trust and support. Even in the few studies where a model of "patron-agent-client" has been revealed, the two parties can still achieve their goals through agents. Nonetheless, these assumptions overlook a basic social fact: due to the segregation of actors and the structural nonequivalence, "structural holes" in the market are more commonly seen in reality than patron-client relations. Though sometimes the client can overcome the structural segregation and form a connection with the potential patron, this relationship may not necessarily be stable and trustworthy. As articulated by Burt, founder of the structural hole theory, "(market) players are connected to certain others, trusting of certain others, obligated to support certain others, dependent on exchange with certain others...By dint of who is connected to whom, holes exist in the social structural of the competitive arena" (Burt 1992:1). North expresses a similar idea in different terms: "the kind of exchange that has characterized most of economic history has been personalized exchange", because under such circumstances, "transactions costs are low" (North 1994:46 [1990:34]). The phenomenon as such still exists in Western market societies, where individualism, spirit of contract and universalism prevail, and we expect it to be even more true in Chinese society, where the transitioning Chinese society, where there has been a legacy of "ethics-centered orientation (lunlibenwei)" (Liang 2005), a tradition of a "differential mode of association (chaxugeju)" (Fei 1998), and the dominance of particularism (Lee 2007).

Therefore, the necessary structural conditions and cultural foundations do not exist to easily establish a connection between the potential patron in the political field and the potential client in the market. Furthermore, as the Chinese government has strived, since market reform, to improve legal institutions and information transparency, incentives from the external institutional environment that would encourage local officials to connect with potential clients have diminished, in spite of the inducement of economic profits. In short, it is difficult for a typical business enterprise to initiate a patron-client relation. Thus, the question follows: how will those potential political patrons and their potential business clients interact when the traditional patron-client connections cannot be established?

In fact, the patron-client relations commonly seen in the market often exist in two forms: primary clientelism and secondary clientelism. Primary clientelism is built from 
a basis of non-segregated and direct interactions between the potential patron and the potential client, and most previous studies have examined this type. In contrast, while secondary clientelism is derived from primary clientelism, it is oriented more directly towards economic interests. Here, the client from the primary relation plays the role of patron in a secondary relation, and his patron from the primary relation may not have any connection to his client in the secondary relation. In other words, the emergence of secondary clientelism relies on the existence of "structural holes" and external constraints, and it describes a particular mode of interaction in a specific institutional setting and with particular market structures. Those business enterprises and entrepreneurs having direct access to political authorities may become patrons in the secondary clientelist relationships and be able to procure market profits from transactions with other enterprises. In contrast, those enterprises without access will become clients in secondary clientelist relationships. If primary clientelism involves a horizontal alliance between the political field and the market field-the core of which depends on an exchange of political power and economic interests-then secondary clientelism entails the vertical integration within the market field, which was established on a mutually beneficial exchange of economic interests. As long as there exist structural holes in the market, those who occupy the hole can take advantage of their structural positions (or those who are aware of the presence of such structural advantages and go after it), thus "creating" the secondary clientelist relationships where they themselves play the role of patrons.

A secondary clientelist relationship is readily distinguishable from the "patron-broker-client" relationship in previous studies. A broker acts as a middleman and arranges an exchange of resources between two parties separated by geographic or personal distance (such as differences in rank or office). A broker is a mediator in an indirect exchange, an agent who does not control what is transferred but who influences the quality of the exchange in negotiating the transfer (Kettering 1988). Similar to a patron in the secondary clientelist relationship, a broker has direct access to the resource provider and gains its trust, offering development opportunities to a client. The essential difference between the two is that the secondary patron profits directly from his transaction with the client while the broker only profits from bridging distances that separate patrons and clients and otherwise stays out of the transaction.

The secondary clientelist relationship comes about as a result of the economic transactions so is not a pre-existing form of social relation or transaction. Having similar characteristics to the two common forms of resource distribution-markets and hierarchical systems-but distinguished from both, secondary clientelism may be a new model in addition to the other two.

\section{Theoretical framework: the interconnected mode between structure and culture}

Sociological research not only identifies new phenomenon but also explains "why", which either relies on existing theories or requires new ones. From the perspective of embeddedness, the secondary clientelist transactions capture a form of structural embeddedness. To explain why this transaction model can facilitate market development, I will now introduce the interconnected mode between structure and culture.

Granovetter argues that the level of causal analysis adopted in the embeddedness argument is rather a proximate one (Granovetter, 1985), which means that only 
through the observation and analysis of concrete and ongoing systems of social relations where economic transactions are embedded, we have the advantage of explaining the micro processes within the market and explicating the formation of a market order at the macro level. However, in the most rigorous sense, the analysis of the systems of social relations is by no means an analysis of proximate causes that ignores cultural and cognitive factors. The reason why sociologists can rightfully assume markets as social instead of natural activities lies in the fact that markets are the product of meaningful human actions involving cultural values about humanity, social actions, and social relations (Slater and Tonkiss 2001). Despite the fact that social relationships constitute an explicit factor that contributes to managing risk and uncertainties as well as to establishing a market order during the transaction process, social relations work only when individuals' cultural values and cognitive insights allow them to do so-more specifically, this requires business ethics. As noted by Warner (1978), in the case of uncertain situations, social actions are often determined by individuals' cognition of social norms, structures, and signals. Business ethics "penetrates the cognition of the actors through socialization and individual cultural markers, influencing their economic practices, and thus the external pattern of the actor's economic activities will conform to a certain structural path" (Fu 2010). Therefore, business ethics, as a kind of market culture produced and reproduced through structuring processes within the market, is not only a kind of "culture in action" (Swidler 1986) but also a kind of culture in structure. Adding business ethics into the structural analysis, we can fill the key gap that has been ignored between structural embeddedness and market development. This is not to indicate that cultural embeddedness and structural embeddedness are juxtaposed with or independent from each other, but to conceive of the former as an intermediating mechanism that cannot be overlooked when we use the latter to explain market development. The key to the realization of market transactions and the establishment of a market order lies in a concrete mode of interconnection and interaction between structural factors (social relations) and cultural factors (business ethics). Hence, it is only through the analysis of the interconnected modes of structure and culture that the network of social relations-as a proximate cause-can constitute a complete and rigorous explanation of economic actions.

Business ethics is defined here as the set of beliefs and values that are upheld and shared by market participants, and which guide their economic practices in terms of interactions with clients and competing with peers. The tradition of cultural interpretivism may suggest different definitions of business ethics. However, a basic agreement states that the ultimate solution for problems of economic efficiency and order lies in market culture, which incorporates the interests of market participants and is compatible with the market field. In other words, business ethics serves as the foundation for market order and is one of the engines propelling market development. Both sociologists and economists concur about the importance of this factor. In explaining the origin of capitalism or the modern market economy, Weber (2010 [1904]) highlights the role of cultural factors and further challenged political and economic determinism. In fact, Weber (2006b [1925]) articulates a set of market ethics that regulates transactions, while North endorses the importance of ideologies that can help overcome problems of speculation and free-ridership (North 1992 [1981]) as well as those of informal constraints (North 1994 [1990]). Some empirical sociological research on markets has 
provided evidence that cultural factors, such as moral values, social norms, meaning systems, and traditional rules, play an indispensable role in the emergence of market institutions, the acquisition of profits, and the formation of new markets (Zelizer 1978, 1985; Ferraro 2006; Fligstein 2008 [2002]; Chan 2009a, 2009b).

From a constructivist perspective (Swidler 1986), particular business strategies can be seen as being constructed on the basis of certain components selected from the "tool-kit" of business ethics, the process of which is also shaped by other social and economic processes. Therefore, even for the same group of businessmen in the same market, their "business ethics" (in particular times) can demonstrate divergent characteristics. Sometimes, as market structures change, the businessman may selectively choose, modify, or overwrite existing and relevant business ethics in order to adapt to the new environment, which will, in turn, manifest itself in a change to business ethics.

\section{The case: lime market of Hui Town}

In terms of methodology, we need a critical case that is theoretically relevant in order to support the argument in this study. A "theoretically relevant" case refers to a case where "the findings can offer feedbacks to the theory and concepts introduced at the beginning of the study, and the feedbacks can either validate or negate the theory, demonstrating either the importance or the irrelevance of the concepts, and they can either expand or restrict the boundaries of the application of the theory and concepts and the importance or meaning of their theoretical premises" (Zou 2002: 253). This is important to construct a proper response to the research question of this article. And a critical case will "provide a particular focal point for disentangling the myth and the contradictions" (Tang 2003).

The lime market in Hui Town satisfies the theoretical conditions stated above. Hui Town is located in the north central part of the Hunan Province, China. Dominated by the construction materials industry and having developed trade and commerce, Hui Town ranks in the top 20 in Hunan Province with regard to economic development. The lime industry has a history of over 200 years in Hui Town. Secondary clientelist transactions and divergent business practices emerged in the lime industry of Hui Town after the mid-1990s (as shown in Fig. 1), allowing a vertical comparison across time, which is the essence of studying a single critical case. The empirical materials in

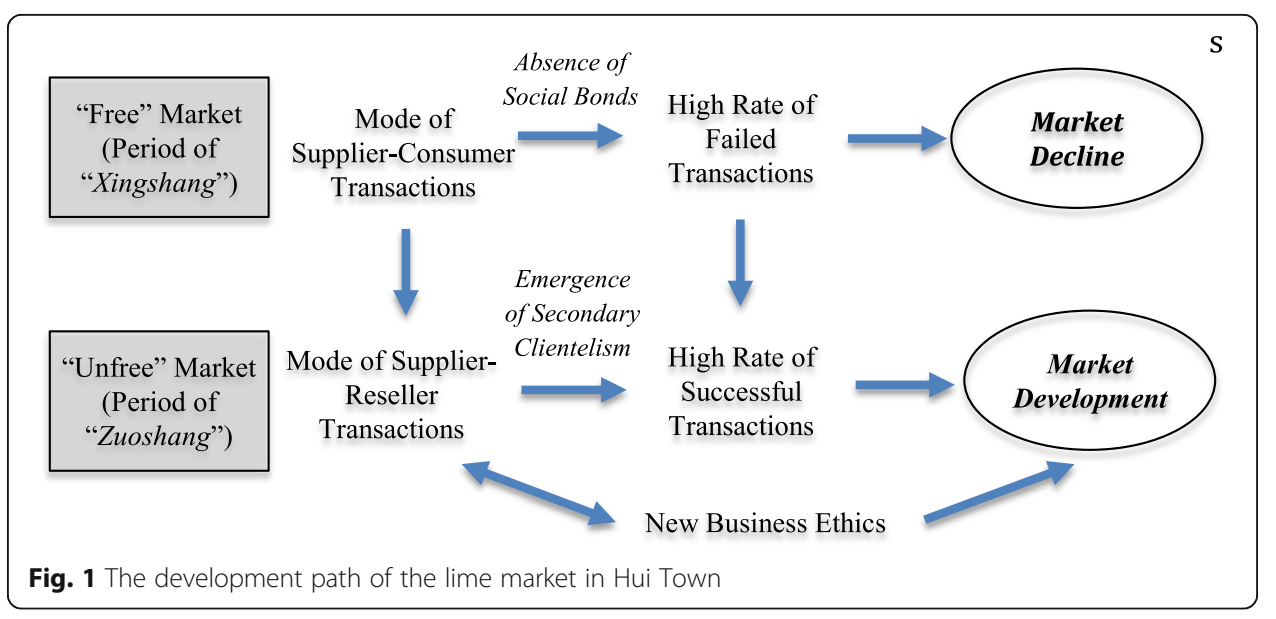


this article are based on a series of fieldwork I did from 2007 to 2010 on the development of the lime industry in Hui Town, and the main source of the material comes from in-depth interviews.

The subjects of interest in this article are the private owners of limekilns, who have been referred to as "huilaoban" (literally, the lime boss) by the local residents. Most of the private owners used to be local peasants, and a minority of them were laid-off workers. According to statistics from the township government, there were 124 limekilns in total by the end of 2009. Most of the limekilns had single owners, while partners owned a few. The reseller, who purchases the lime from the limekiln owner and sells it to the client who has a demand, making profits from the buy-sell price spread, is known as "tilanzhe" (literally, the men who carry the basket). Lime resellers specialize in the business of so-called "tilan" (literally, carrying the basket), and they often had a stable partnership with a specific group of limekiln owners and made sales to particular clients. The fact that structural holes existed between the supplier and the big clients causes the reseller to be the patron in a secondary clientelist relationship. In fact, they have higher market status than lime bosses who produce the lime, as they could always provide market opportunities for large-scale transactions to the lime kiln owners, securing their profits, and meanwhile establishing their power through the dependence of and gratitude from business owners. ${ }^{2}$

\section{The risk and uncertainty in the stage of "free" market}

In general, business owners from the lime market in Hui Town have experienced two stages since market reform: from xingshang (literally, running around for business) of "free" market to zuoshang (literally, doing business while sitting) of "unfree" market. The first stage lasts from the beginning of market reform to the mid-1990s, and during this time they have to send salespersons to search for potential clients and contact buyers; the second stage lasts from the mid-1990s till 2010, and during this time, they do not need to actively search for clients and the transactions are made through lime resellers by phone.

\section{Direct local transactions: internal competition and the risk of credit sales}

At the beginning of the 1980s when private enterprise started to enter into the lime market, those private business owners not only had to compete for a market share of the lime market that had been monopolized by state-owned enterprises for decades but also needed to expand their client networks and search for new demand. This was a time when there was shrinking demand for lime, as agricultural chemicals had increasingly replaced it and the demand for lime in the construction industry had not yet taken off. As a result, the emerging business owners had a hard time improving their sales. Typically, the owners of limekilns would have to send out several professional salespersons that would search for clients by knocking on doors. In addition, they would need to hire a few persons to wait and watch for potential clients at the main crossroads in town and then compete for clients with other producers. For example, in a village named Yunque, there were 40 limekilns in total in the early 1990s, and each owner would send several salespersons to wait at the crossroads. One of those people 
who used to wait and watch for clients described the scene as "(we were) just like a group of ducks crouching under someone else's roof."

As the business in the lime industry was down, there were often conflicts between business owners who were fighting over clients. However, if one lime boss took over a client from his competitors by intentionally underpricing, this act that was termed "waqiangjiao" and was deemed unethical. Though sometimes this kind of behavior might result in a successful "raid", the lime boss who adopted such strategies would be shamed by their peers and condemned by the public. In addition, the victim would often follow the rule of an-eye-for-an-eye and seek revenge at all costs. The main purpose of this retaliation, however, had little to do with economic interest, and served only to teach the offender a lesson. Consequently, lime bosses did not typically take the action of sabotaging by underpricing unless the business was extremely soft, such as in times of economic downturn; in contrast, those lime bosses who highly value morality and business ethics would never use strategies deemed unethical.

For example, during an incident of being sabotaged by underpricing, a lime boss named LJF lost one of his former clients, someone with whom he had maintained a long-term partnership. In return, he retaliated by taking over the offender's clients with a shockingly low price-even lower than production expenses. Although he successfully achieved his revenge, his action was not aimed at taking back his clients (that is, not oriented towards economic interests) but instead aimed to express his anger and to make it clear that this kind of behavior was unethical. He admitted that the reason why he was enraged was because the offender "disrupted the market order". So when the former client who "betrayed" him wanted to do business again, he was no longer willing to respond.

Due to stagnation in sales, many lime bosses allowed their clients to purchase lime on credit. In this case, often they would not be able to receive payment by the due date, and they would need to send out someone to collect payment. Even so, bad debts were inevitable. Some clients defaulted as a result of their own difficult economic situations-for example, some peasants were burdened with a huge amount of debt when building their own houses, and some factories and collective enterprises had low revenues and even entered bankruptcy. If they chose not to default, they would pay the debt by alternative means. For instance, they might pay using valuable assets or agricultural products. Most business owners would have to accept such types of payment once they had confirmed that the client was indeed out of cash and realized that forcing the client to pay would only result in poor outcomes for everyone.

At the beginning of the 1990s, many local peasants started to build their own houses. However, most of them neither had sufficient financial nor material preparation. It was quite common for these peasants to purchase building materials on credit. In some other cases, the actual expenses of building the house exceeded their original budget. As a consequence, many peasants could not make payment and had to use whatever they had to pay off the debt-whatever was available when the lime boss came to their doors to collect money after the harvest season or at the end of each year. Recalling such experiences, many lime bosses said that "it's typical for local peasants to build houses with credit purchases, and money is not a significant concern for them". When it was extremely difficult to receive payment in cash, they would have to take household goods or livestock. Most lime bosses had similar experiences during this time. 
One of them joked that such transactions were literally a "barter economy" and told me the story of how he took grain and pigs from a debtor and then traded them to a raw material supplier in order to clear his own debt.

\section{Non-local transactions and its risk}

At the first stage, non-local transactions also might be prone to induce risk since lime bosses often needed to conduct sales out of town and deliver the goods to the client's door. The risk associated with this type of transaction could often multiply, and problems of bad debt, doubtful debt, and even fraudulent transactions were quite common. In a small sample survey, we asked lime bosses the following question: "As far as you know, which time period was marked by a peak of fraud occurring in the lime industry in Hui Town?" Among the 32 respondents, 18 of them chose the time period of 1990 to 1995, and eight chose the period of 1996 to 2000. In total, almost $75 \%$ of our respondents, or three-fourths of the lime bosses, agreed that fraud happened most frequently during the 1990s, which indicates that this was the most uncertain period for business transactions. In addition, 25 out of 39 respondents declared that they had been victims of fraud themselves.

In their slang, the risk of doing non-local transactions was termed by lime bosses as "huodaoditousi" (the value drops once the goods come to the door), meaning that if the seller delivers the goods to the buyer before the two parties have reached an agreement with regard to the details of the transaction and the seller does not have a backup plan, then the buyer may take the advantage and bid for a lower price, or even reject the transaction. In this case the seller would be mired in a dilemma-on one hand, it would be difficult to find a new buyer in a totally unfamiliar place even if he is not satisfied with the new bid; and on the other, the seller himself would incur the cost of time and transportation if he decides to take back the goods. As recalled by many lime bosses, it was common to be forced to sell at a lower price once the goods had been delivered to the non-local clients.

This phenomenon continues to have a deep impression on many lime bosses. There is one account widely shared among lime bosses-“don't pour the lime into someone else's tea garden", which refers to an incident that happened at a time when sales were extremely difficult and the seller did not reach an agreement with a non-local buyer. They often joked about the story, as it was not only a way to poke fun at themselves but also a self-reminder-there is always a risk whenever the seller makes a non-local transaction without thorough deliberation. The experience of a lime boss, Mr. Wang, who was the archetypal character in the story of the tea garden, vividly demonstrates the dilemma of "huodaoditousi."

If we deliver the goods to someone else's door on our own, the person would have leverage over you. There was a guy who, in 1995, set off to send lime to Wanmang, but it did not get sold, and then he sent the lime to Ruanjiang (where the lime was not sold either), and finally to Hanshou where still nobody was interested in buying the lime. This guy got so irritated that he simply poured the lime into a local tea garden-he was planning to empty his truck on the way home to save some money on gas. Then the owner ran after him and questioned: "who told you to pour the lime? It will kill my tea trees." Eventually, he had to lie that it was not him who did this. This is called 
"huodaoditousi". Once we deliver the goods to the client's place, we will be at their disposal because they do not think we will want to take it back, just like this idiot who had to throw away the lime himself and ended up without even a penny-because the lime would be totally useless even if he dragged it home (Interview record 20090810 - LYB).

In addition to the dilemma mentioned above, lime bosses also often faced the risk of fraud. Though the form of this type of risk differs from the previous one, the essence and the cause of it basically resembles that of the above phenomenon. From the account of a lime boss who actually experienced fraud, we know that the transaction failed under the circumstance of a fake formal transaction where the client had already signed a contract. When the lime was delivered to the client as agreed, the client received the goods but defaulted on the rest of the payment, or perhaps never had the intention of paying. In this case, lime bosses could hardly do anything but blame their own bad luck. In addition to the risk of payment default, local gangs or drug addicts might try to extort money from them during the delivery process, as non-local businessmen were often the targets of robbery and physical violence. As a result, some lime bosses said that "frauds were prevalent in every place in those years, and it was a broken order" (Interview record 20090814 - LQQ). Another lime boss, who has been in the lime business for over 20 years, revealed that he essentially did not make any money until 2000, because "(the money) all went into the pockets of the swindlers" (Interview record 20090817 - LRJ).

\section{The new mode of transaction in the stage of "unfree" market New groups and new relations}

According to lime bosses, the lime business has become much easier since the mid-1990s-frauds have declined significantly, and the lime market in Hui Town has entered a new phase with very stable transactions. Though there might be multiple explanatory factors for the changes of the market, the emergence of a new group, the lime reseller, has played a key role. The previous face-to-face transactions between the lime boss and the client have been replaced by transactions between the lime boss and the reseller, and between the reseller and the client. Despite that lime resellers as a special business group, perform actively in the market, they were often "invisible"-as they seldom travel to Hui Town in person and negotiate business with lime bosses face-to-face. However, this has never hindered the reliability of the transactions (the reasons will be discussed in detail later). Most of the lime bosses agreed that resellers played a critical role in the formation of a stable market order.

The emergence of the reseller was an immediate response to the explosive demand for lime in the government-sponsored infrastructure building process. The major and mid-level cities in the Hunan Province started infrastructure building on a massive scale beginning in the mid-1990s, and the demand for lime was driven up as a result. Meanwhile, the demand for lime in the pulp and paper industry and the steel industry also grew quickly as the economy took off. In fact, it is fair to say that the biggest client of the lime market was the government at that time, more specifically, local governments that were responsible for infrastructure development and state-owned enterprises. Typically, such projects were outsourced to local municipal engineering and construction companies (for example, Changsha Municipal Engineering Company) 
through a bidding process. As a result, the company would become an immediate client for the lime business once it took on the project. One of the resellers told me that it was possible for a company to take multiple projects without bidding if the boss had connections with some government officials, and even with bidding, the process would hardly make any difference as the result was determined by networking.

As for why certain companies would finally take over a project, it was hard to tell. Anyway, the company that took the project would need to purchase raw materials. For small companies, the boss would take charge of the purchase himself. However, large companies would designate particular functions or send out personnel to purchase lime. In this case, the information on the demand for lime immediately flowed to those who had connections (for instance, friends and relatives) with the government officials or the designated purchasing personnel within the company. Once they became aware of the potential opportunities, they would manage to communicate with the company through formal and informal channels and undertake the business. As a result, this group of people became resellers. Many lime resellers only came to be acquainted with their connections in the construction company through formal business; however, the two parties often established a friend-like relationship with a high level of mutual trust through long-term cooperation. Though it was by nature an instrumental relationship based on an exchange of economic interests, the two parties would manage to enhance the emotional base in order to secure the stability of relations as such. In the end, the emotional investment through various forms-such as dinner invitations and holiday greetings, served to reduce the instrumentality involved in the relationship and transform it into an emotional one.

Those resellers who directly completed transactions with the client represent only the first strata of this group. Not only did they have an advantage in terms of social networks but also economic means-as they often had to pay a large amount of cash in advance to secure lime from suppliers (despite the fact that it was possible to purchase lime on credit, the down payment was still a large sum of money). If they were sufficiently familiar with the lime market and able to evaluate the quality of lime themselves, they would contact the suppliers directly - this is why the suppliers might sometimes have a lucky encounter with "caishenye" (God of Wealth). However, most of the resellers did not have enough expertise to evaluate the lime's quality and had to rely on friends or relatives who were familiar with the industry during the purchases. In this way, the second and the third strata of resellers appeared. The transaction chain might extend to a great length for a large-scale business. Take a highway construction project for instance: lime demand was strong and a construction company often offered a very attractive price, and it was almost impossible for a typical supplier or a regular reseller to obtain such a highly profitable project. As a result, it was often the case that the lime from Hui Town went through several transactions by different resellers before being delivered to the customer.

Therefore, the distribution of business information, resources, and profits was still based on social relations despite the vast business opportunities available during the period of infrastructure building. In fact, most of the lime bosses came from the peasant class and lacked direct connections with government officials, local municipal engineering or construction companies; it was only through the reseller that the transactions were possible. This can partly explain why, as disclosed by many lime bosses, 
the lion's share of the profit actually went to those resellers and they themselves only received a minimal share. Another important reason lay in the lack of confidence from lime bosses in terms of having direct transactions with the client, as they deemed such transactions insecure. In turn, the clients also doubted whether lime boss would provide high-quality lime, but they trusted resellers.

A lime boss said: we often do not do direct transactions with big clients, because if I did not know him well, it would be easy for him to play tricks and deceive me. In turn, he (the client) would also need the reseller-the lime provided by the reseller is often more reliable and of higher quality, and he (the client) would be willing to pay $10 \mathrm{RMB}$ (approximately US\$1.5) or even more for a ton of lime. If he (the client) bought the lime himself, the quality would not be as good-the lime would contain more contaminants and other remains. Once a client came to the door, the producer would manage to take advantage of the client. When there was nobody willing to buy the lime, the producer would have to turn to the reseller for help. This way the reseller would establish a reputation between the client and the supplier. For instance, if you were the supplier, a reseller would come to you and ask "how's the quality of your lime? Give me the best you have." Because you will rely on him to sell the lime, you would offer lime of high quality. From the perspective of the client, he would also turn to the reseller because the lime provided by the reseller is definitely better than that from a direct purchase-with fewer stones and contaminants. Even though the reseller might ask for a higher price (than the price asked by a supplier), the client would still accept it regardless of the price, as long as the quality of the lime is reliable (Interview record 20090808 - GWS).

According to one interview, the lime reseller first appeared around 1995 or 1996-but only a few, and transactions through resellers were nearly equal to transactional mode of supplier-consumer during that time. At the turn of the century, more lime resellers entered into the industry, and they increasingly became dominated players in the market. Resellers often kept long-term business partnerships with multiple producers in order to guarantee a sufficient supply of lime, and their clients were often those who with a huge demand for lime-for instance, construction companies, industrial enterprises, infrastructure building companies, and so on. The reason why lime resellers could play the role of patron in terms of their relationship with suppliers was not only due to the abundant economic resources they possessed but also because of their widespread connections within local governments and within the market. Most of the time they came to lime bosses with large orders. A lime boss described one of the typical ways in which lime resellers handled their business.

The reseller that I have been working with mainly deals with the mining industry. They (the enterprises purchasing the lime) often do not have enough cash and the reseller will have to pay for the lime out of their own pockets ("pudi")—for example, 100,000 RMB (approximately US\$15,000). Then, they get in touch with the supplier and sign the contract. The contract typically lasts for a year, which means the reseller will provide lime to those mining enterprises on a regular basis during the year. The reseller also needs to promise that they can deliver the lime upon request at any time so that production at the mining enterprises would not be interrupted (due to the delayed supply of lime). They normally can get 30 to $50 \mathrm{RMB}$ (approximately US\$4.5 to US\$7.5) per ton of lime as profit; however, they will have to pay for the lime out of their own pockets at the very 
beginning, as their clients are not able to clear the bill by cash immediately. It is typically the case that the clients fulfill all payments in 1 month or pay an installment every 3 months, and alternatively, they can request a credit of 100,000 or 200,000 RMB (approximately US $\$ 15,000$ or US $\$ 30,000$ ), which means they would not start to pay until the amount payable reaches 100,000 or 200,000 RMB. After that, they will pay each time when the lime is delivered. And the person who is responsible for purchasing lime, such as the head or the manager, can also earn a profit of about 10 RMB (approximately US\$1.5) per ton of lime (Interview Record 20090810 - GY).

The supplier and the reseller cooperate for the sake of "mutual benefits." Because lime resellers can bring lime bosses business and revenues in a secure manner, the latter all deem it reasonable for resellers to reap a larger profit than what they earn. If the suppliers went to the clients themselves, on one hand, it would be difficult for them to get the order; and on the other, even with an order, it would still be difficult for them to guarantee that the clients would eventually pay. According to some lime bosses, "he (the reseller) deserves the profits. I sell the lime to him based on the average price on our local market, and it won't be necessary for me to know how much profit he makes out of his transaction to the client." (Interview record 20090810 - LYB) “... It's mainly based on mutual benefits-when you deliver the lime to him, the profits are out there for him, so it won't be a concern that he might not pay back the money" (Interview record $20090313-$ LMQ).

\section{New modes of transaction}

When lime resellers emerged, there appeared multiple layers of transactions between the lime suppliers and the customers-with the supplier of the suppliers and the customer of the customers involved, the chain of a transaction was largely extended. In fact, the emergence of secondary clientelism makes it redundant for formal agreements and contracts during the transaction-the suppliers and the reseller all rely on "oral agreements" to settle a deal, which proves the mutual trust between the two parties.

One lime boss described: now if someone owes me hundreds of thousands of RMB, they do not even need to leave me a note. All the contracts, except the ones for outsourcing, are all based on oral agreements. For now, we mainly deal with those people who we had previous transactions and are reliable, and we maintain good relations... for instance, the large deal we had last year with a coal mining company was introduced by a friend, and all the transactions we had were made through oral contracts, which often involves millions of RMB. At once, he owed me several hundreds of thousands of RMB, but he paid back most of the debt by the end of the year. So when he was still short of a couple of thousands of RMB at the end of last year and he proposed to give me a note, I just told him not even to bother, as long as he remembers to pay me back in full next time (Interview record 20090313 - LMQ).

Furthermore, lime resellers seldom showed up in person in Hui Town to evaluate the lime. Whenever there was a need for lime, they would get in touch with the lime boss by phone. Once the amount and the price (including transportation) were settled, the lime boss would send out drivers to deliver the lime to the designated place within the time scheduled. After the lime was transported out of the factory, the supplier would keep detailed notes about the transaction in order to arrange for payments from the 
reseller in the future. Often the reseller would not pay cash immediately after they received the lime, and it was typical to purchase on credit. Nowadays, transactions done through credit occupy a larger proportion of the total than before. In spite of the fact that the two parties never documented the contract on paper, the chance of bad debt happening is now much lower than it used to be.

Transactions done on credit mainly took the form of "pudi", which varied in three ways. The first was to keep some amount in the first transaction unpaid while the reseller would have to pay in full in cash every time when the lime was delivered to them. The unpaid amount was called "pudi". In the second case, there was no "pudi" during the first transaction and all payments were fulfilled in cash. When the lime boss developed trust in the reseller, it would be possible for the reseller to "pudi" upon request. In this case, the "pudi" would consist of a certain unpaid amount each time when the lime was delivered. For example, if the lime was valued at 5000 RMB (approximately US\$750) for each delivery, a portion of one fifth might be kept unpaid and would be documented as a "pudi". The second scenario mainly applies to those resellers with newly established relationships. For those resellers with long-term cooperation, the supplier would often demonstrate a higher level of trust and dependence. Some lime bosses even approved a "pudi" with an amount of several hundreds of thousand RMB, as long as it was cleared at the end of the year or during traditional festivals. Therefore, for those resellers who always provided big orders over the years, the transactions were often initiated through credit and all the payments were eventually cleared over a short period of time. Sometimes if those lime resellers had abundant cash, they would clear the debt once in a while. The third scenario involves paying a designated proportion of cash upon each delivery and leaving the rest as "pudi", and all the debt should be cleared when it came to certain time points such as holidays or festivals. According to the interview, most of the clients who purchased on credit were those with a demand for industrial lime and those in the road and bridge construction business, and their demand for lime was among the largest.

In fact, lime suppliers had already become accustomed to purchases on credit and various forms of "pudi". Despite the fact that payments were not settled immediately at the time of delivery during these transactions, there was no need to worry that the debt might not be paid back. Even though the payments were delayed sometimes, lime bosses would attribute it to the third party and would not blame the reseller-as lime resellers themselves might get caught in problems of bad debt and cash flow shortages.

Many of the payments get delayed because people from the construction company cannot pay back the debt they owe the reseller, and the reseller has to delay the payments that he owes me. He needs the money to grow his own business, so he takes advantage of ours. We have to keep on handling our transactions with him, as we have already been "hanging" onto this and there is nothing we can do about it (Interview record 20090313 - LMQ).

Relevant to this, a lime reseller also revealed his situation:

Nine out of ten businesses in road construction require "pudi.". We normally pay for about $60 \%$ of the lime, and the rest has to wait until the end of the year or the (important traditional) holidays. Debts are quite common, and there is no debt that we have failed to take back. If those people can afford to build a road, what is the point for them to owe you the money for the lime? It is only because they sometimes have trouble 
with cash turnover and have to wait until the New Year or the holidays. When the client has a particularly huge demand for lime and we do not have enough cash to purchase the lime from the lime boss, we have to borrow money everywhere, and sometimes we just owe it to the lime boss. It is possible to purchase some lime on credit without any cash-after all, I have had some reputation in the local market. I may have owed many suppliers here and there. It is almost impossible to have no debt at all (Interview record 20090816 - LSH).

Some lime bosses mentioned that the reseller used to get his business rolling again through the money from his "pudi" with the supplier; however, most of lime resellers had turned to cash transactions in the last several years, except when the demand for lime was so large that it exceeded what they could afford to supply. There were two reasons-one is that the reseller had more economic resources at their disposal, and the second is that they wanted to avoid scenarios in which their clients might be taken over by the lime boss who might investigate client backgrounds (Interview record 20090810 - LYB). Nonetheless, those resellers with fewer economic resources still needed to get their business rolling by purchasing on credit or through "pudi" with the supplier, as their clients who demand lime often require "pudi" during transactions with the reseller. Thus, there appears a triad of debt, where the reseller owes the supplier and the client owes the reseller. Only when the client pays back part of his debt with the reseller can the reseller clear some of the debt with the supplier.

\section{Changes in business ethics}

\section{Business ethnics in the stage of "free" market and dilemmas during transactions}

As my informants reported, the reason why transactions often failed during the first stage was that suppliers had to take risks when selling their products if the demand was low. As a result, failure in transactions was common in long-distance transactions when the supplier delivered goods to the door of the client and when the client requested that they be allowed to purchase lime on credit. After the reseller entered the market, it was still typical for suppliers to deliver the goods to the client's door and for clients to purchase on credit. However, the results were totally different despite the proximate transaction mode in two different periods-with a high rate of failure during the first stage and a high rate of success after. The reseller's entrance into the market actually breaks down the one-time transaction into multiple "small transactions" and extends the chain of lime transactions. Theoretically, the extension of the transaction chain, especially with multiple transactions based on credit, would indicate an increase in the risk and uncertainty of the whole transaction process, and the market would demonstrate a higher level of instability. On the contrary, what we have observed shows that the emergence of the reseller enhanced the stability of the transaction and helped to promote market development. Why did this happen? To answer this question, it is necessary to re-examine the dilemmas that appeared in the previous transaction mode and compare them with those in the new phase in order to capture the particular characteristics of the new transaction mode.

Using their own language, lime bosses identified an economic principle-failures and frauds in transaction were due to a buyer's market in an economic sense; the later emergence of a stable market order was the result of the development of a seller's 
market. In fact, the ultimate cause of these phenomena cannot be attributed to the existence of a buyer's market before the mid-1990s. Even when a buyer's market has appeared since the 21st century due to an abundance of supply in the lime market, the phenomena described have seldom occurred. From my observations and analysis, these phenomena have their roots in the prevailing business ethics of "zhongliqingyi (valuing interests above justice)", in which people are oriented towards material interests with little regard for moral principles.

Many lime bosses mentioned that neither they themselves nor their peers had much regard for morality back then and only focused on short-term interests: they were so myopic they could not see the importance of their business reputation and were only interested in tiny profits. When individual peasants came to them and purchased lime on credit, they always took advantage of those peasants who had little experience in buying lime and lacked the knowledge to evaluate its quality, even though it was very likely that the peasants could pay on time. When dealing with non-local clients or clients with whom they were unacquainted, they sought every chance to maximize their own profits through unethical conduct such as blending lime with other contaminants, playing tricks with the actual amount of lime, and so on. These tricks were partly due to their motivation to maximize profits and were induced by the lack of regulations and law enforcement. The following account came from an interview with one of the lime bosses.

The client normally did not have direct transactions with us back then, as they would often be deceived once they directly came to us-because most of them did not know how to evaluate the quality of the lime, and it was very likely that the lime they bought was actually mixed with some lime of poor quality or other contaminants. Why was the business back then not as good as the business nowadays? One reason is because of us, who produce the lime-we had little regard for morality and always blended lime with other contaminants. The person who needed lime-for instance, he might need 50 tons of lime to build his own house-came to us in person, avoiding the mediation of a reseller who could make some money out of it. However, he did not know how to evaluate the quality of the lime himself and was not able to distinguish those of good quality from those of poor quality, because he had little experience using lime. After bringing home the lime he purchased, he would find out that the lime was almost useless because there were too many contaminants (Interview record 20090314 - LYX).

As a consequence, it was impossible for the two parties involved in the transaction to establish a relationship based on mutual trust, and this led to a high rate of failure for lime transactions. Many cases provided evidence that there was a lack of interpersonal trust between the two parties involved in the transaction. Without a doubt, trust is of great significance for market transactions and economic development. Despite its importance, trust is only a precondition for completion of the transaction to proceed and not the engine that directly generates stable and continued market transactions. The existence of trust or formal contracts does not guarantee that the supplier would not be deceived by the buyer or that he would not be stuck with bad debts-as can be demonstrated by the experience of a lime boss, LQQ, as previously described. In addition, the existence of trust cannot explain the phenomenon of "shashu (taking advantage of an acquaintance, literally, deceiving a familiar person)". It is possible for the trust between two people who are familiar with each other to be exploited in an 
instrumental way. According to a lime boss, a trusted acquaintance purchased lime from him on credit a couple of years ago, but the person still owed him about 80,000 RMB (US\$12,000) today. Though the person acknowledged his debt, he never planned to pay him back (interview record 20090811 - SWJ).

Therefore, interpersonal trust cannot be regarded as an ultimate cause for fraud and default. In fact, a more convincing explanation can be derived from the perspective of game theory. From the point of game theory, it is in a single game that fraud and default can occur-the buyer does not have the intention to develop a long-term partnership with continuing transactions. Thus, it is in the best interests of parties, buyer and seller alike, to adopt the strategies of fraud and default in a single transaction. So in the case of a single transaction, the supplier is disadvantaged when the transaction is based on credit or when he delivers the goods to the buyer's door, and the buyer can take advantage of the supplier through their own optimal strategies-forcing the supplier into a lower price, deceit, fraud, or breach of the contract.

Accordingly, it actually changes in the people involved in the transactions rather than change in the demand for lime that has led to the stability of transactions and the upturn in the lime business. In the first stage, it was a difficult time for the lime supplier, and most of the demand came from individual clients with small construction projects and local peasants who built their own houses. In this case, the supplier had to go out and actively search for customers. However, most of the clients had limited purchasing power and most transactions were one-time only. Without an expectation for repeated transactions with the customer, the supplier faced a high level of risk and uncertainty. In the mid- and late-1990s, the demand for lime mainly came from the government, large enterprises, and big companies, who tended to establish a long-term cooperation with the lime suppliers (though in fact most of them partnered with the reseller rather than the lime supplier directly). What is more, enterprises and governmental organizations held a stronger motivation to maintain a good reputation, which might further facilitate a smooth transaction. With the explosive growth in the demand for lime from industrial construction and infrastructure building in large cities, not only did buyers possess greater purchasing power (as described by a lime boss "when the lime got sold out quickly and business became much easier, people were very generous with their money"), but also vast opportunities emerged for long-term partnerships. As the transaction mode of reseller-supplier frequently involved repetitive transactions, each transaction resulted in a higher level of stability.

Nonetheless, the existence of trust remains a necessary condition for transaction stability and even the emergence of a market order at the macro level, though the lack of trust cannot be regarded as the ultimate cause of actions intended to defraud or default. A transaction will not be initiated if the buyer lacks trust in terms of the quality of the goods and the seller lacks trust in the buyer's ability to fulfill payments, in which case there is no foundation for maintaining or operating the market.

\section{New business ethics in the stage of "unfree" market}

Interestingly, many lime bosses concurred that there existed an implicit causal link between the emergence of lime resellers and the formation of a stable market order. In fact, the reason why lime resellers were able to promote a stable market order can be 
found in a new type of business ethics embedded in this transaction mode-the business ethics that values good reputation and morality, with an emphasis on social interactions in non-economic realms and mutual benefit.

\section{Reputation and morality}

Lime resellers enjoyed a good reputation among lime bosses from the very beginning, despite the fact that most of the resellers were non-local and the majority of them came from Changsha. From the standpoint of the lime bosses, Lime resellers were a group of reliable and trustworthy businessmen. Many lime bosses mentioned in the interview that those resellers "have a high regard for reputation and are trustworthy... ... (We) have been dealing with them for years and know what kind of people they are. They are real businessmen who won't play tricks on us" (interview record 20090310 - LYS). "In fact, we trust resellers-they always stick to their promises, except those who intend to take advantage of you" (interview record 20090810 - LYB).

Under the influence of the reseller, the ethics of "shangzhongyi, buwangli" (businessmen pursue profits without dismissing morality) came to be regarded as important, and suppliers started to recognize the significant role of reputation and morality in a successful business. During the interview, they often acknowledged the effect of those abstract values and moral principles-such as maintaining a good reputation, being trustworthy, just, and honest, on their business outcomes. As a result, a supplier who possessed a good reputation and an agreeable character would even have an edge over a supplier who could only offer a lower price in the market competition.

As some lime bosses said: sometimes when your (selling) price is cheaper than that of others, (the client) still would not buy your product. Reputation and interpersonal relationship play a significant role. Additionally, having been involved in the partnership for so long, (we) have developed mutual trust. People in the city always sign contracts, and rural people rely on oral agreements. For (us) rural people, it entails honesty and trustworthiness to save face-you must keep your word. Once you fail to do that, you will lose your face, and there is no way you can continue a business without that (Interview record 20090313 - LMQ).

Those lime bosses who are successful in their business all rely on their networks and personal character. Those who are good at managing their own business and make a fortune all have high regard for their reputation and are able to stick to their words-even with clients who have little knowledge about lime, they never fake high-quality lime with that of poor quality and sell it to their clients (Interview record $090811-\mathrm{DBQ}$ ).

Their observation also indicated "even with many friends, your (business) still can't survive without a good reputation" (interview record 20090819 - CGY). It is with such a foundation that oral agreements and transactions based on credit became norms among the suppliers and the reseller, with whom they maintained stable partnerships. In the past, failure in nonlocal transactions occurred frequently to lime bosses when they delivered the lime to the client's door. However, why did this problem become less of a concern for lime bosses? And why were they willing to deliver lime immediately upon the request from a lime reseller even they were not quite familiar with each other? Although they all had some elusive accounts, most of the lime bosses could not identify the specific reasons behind this change and described it like this: "it is a kind of "mystery"-the reason why we trust those resellers mainly has something to do with their personality. Our nation has an ancient history, you know, there is something out 
there that cannot be explained explicitly. This is a sort of folk wisdom. I just can't tell exactly-there is an intuition which tells you that this person is accountable and there shouldn't be any problem with selling him lime" (interview record 20090314 - LYX).

As the saying goes, "yi, liye (profits come from justice)", "qizha huishi, xinyu xingshi (fraud causes the market to crash, while trustworthiness brings the market prosperity)". Those who valued their reputation and maintained their integrity rapidly made a fortune during the wave of economic development, and thanks to the establishment of this new type of business ethics, the lime market in Hui Town boomed. Therefore, from the perspective of the lime supplier, the transition from a market order with risky transactions into one with greater stability also suggests a process where a business ethics that emphasized good reputation and trustworthiness came to be established. Though a high level of marketization can promote trust among strangers (Tang and $\mathrm{Fu}$ 2008), the mutual trust and business reputation that existed could not grow out of the air-they came from economic and social interactions between suppliers and the reseller under the circumstance of a changing market. To a large extent, the intense secondary clientelist network that developed among these suppliers and resellers was a product of the uncertain economic environment and the flow pattern of market resources dominated by a particularistic trust.

\section{Social interactions in realms outside economic transactions}

Many lime resellers were very good friends of lime bosses. Though lime bosses did not have to deliver lime in trucks themselves, they often went to the city with the trucks or drove their own cars in order to meet with the reseller, enhancing mutual trust through various activities that strengthened the emotional intensity-for instance, inviting the reseller for dinner, playing cards together and having fun, sending local souvenirs as gifts, and so on. And those resellers who became good friends of the lime boss would also give something in return-not only in terms of providing economic benefits through formal lime transactions but also exchanging favors in social interactions. For example, one of the lime bosses, Mr. Liu, celebrated his birthday several times with two resellers, with whom he maintained very strong friendships. These two resellers would always come over to Hui Town with gifts, and Mr. Liu would invite them for dinners and furnish them with gifts of high value (typically liquors and cigarettes) in return.

During the field investigation, one of the workers in a lime factory joked that his boss had a very successful business-with a good personality and lots of friends, but in fact this boss only turned his own money into his profits, because he often lost several thousand RMB to his resellers when playing cards together. And his boss, also told me that he had lost tons of money on card tables when he started his lime business-in 2002 alone, he lost over eighty thousand (US\$12,000). Though not very outspoken, he was quite generous and thus had many friends. As a result, his business ranked top among all the lime bosses in Yunque Village. He often said "I earned my bread by friendship".

As a positive consequence of establishing social bonds in addition to economic relationships, an ethical ingredient was woven into the transaction process-despite the fact that the two parties involved did not explicitly state their motivations. Thus, the "pure" economic transaction became "impure", and the business became more "caring" among friends instead of just being a business. Accordingly, the exchange of favors, as a type of social exchange, not only facilitated mutual knowledge and trust but also gave 
rise to the principles of interaction and network features that resemble those in a faceto-face society, thus transforming the anonymous and impersonal orientation in the market field towards purer transactions.

As Blau (2008:150 [1964:94]) puts it, "only social exchange tends to engender feelings of personal obligation, gratitude, and trust; purely economic exchange as such does not". The suppliers acquired confidence in the security of the exchange and developed an expectation of continuing transactions, the expression of which can be seen from the prevalence of transactions based on credit and through "pudi." Furthermore, the intense social interactions and the exchange of gifts between the supplier and the reseller, which were derived from the friendliness and politeness that the two parties tried to demonstrate, equally enhanced the mutual knowledge about each other's personality and moral character. As underlying norms and moral principles regulated the social interactions in non-economic realms, future transactions and business partnerships would be built on a solid social basis, ${ }^{3}$ because "the production of guanxi simultaneously creates human feeling and material obligation. The more ganqing there is, the closer the guanxi. The closer the guanxi, the more it can be relied upon to bring economic, political, and social benefits. Such benefits in turn produce stronger guanxi" (Kipnis, 1997:23).

Spiders weave their webs for food. The lime business owners built their webs of relationships to occupy a vantage point in the market and establish their competitive advantage. Once the economic relationship was enriched by friendship ties established through emotional investment and exchange of favors, it gave the business owner an edge over other competitors so that he would not be kicked out of the game, even in a scenario where others try to sabotage by underpricing. To some extent, the supplier's strategy of overcoming transaction dilemmas through social interactions was a result of their lacking a sense of security and confidence in non-local transactions. Therefore, the secondary clientelist network can be understood as "borne out of distrust (of the externals), not trust (of the internals). Chinese business networks are best conceptualized as a group strategy—not to build trust per se, but to cope with distrust" (Chan, 2000:9-10). Consequently, despite the fact that the transaction between lime bosses and resellers was still based on the market price, the relationship became emotionalized and socialized due to the reseller's trust in lime quality and the previous successful cooperation between the two parties. In this way, the supplier no longer worried that the reseller might take advantage of him or other competitors might sabotage the transaction.

In short, the way in which the reseller profited may be seen as an erosion of the interests of both the supplier and the customer on the surface-as they bought at a low price from the supplier and sold at a high price to the customer, while, in fact, they played an indispensable role in market transactions. It was their existence that decreased the risk and uncertainty involved in the transactions, and this also explains part of the reason why the reseller enjoyed certain power within their relationship with the supplier.

\section{The generative mechanism for the business reputation of lime resellers}

A question that immediately follows is: how does the reseller gain their reputation and power in the market? As for this, lime bosses had various accounts based on their own experiences, and these offered multiple explanations. The first explanation can be referred to as the mechanism of peer monitoring-a process in which the supplier will 
have a rational evaluation on the trustworthiness of the reseller (the subsequent trust generated from this process is known as "cognitive trust"). On one hand, a lime boss can develop his knowledge about a lime reseller before their first transaction through other resellers; on the other, if the reseller has had a record of playing tricks on a lime boss, the information will likely spread through the peer network in the lime business, and the reseller will be punished by this negative information.

After all, we all had a widespread network of peers and customers, and resellers fall within this network. I can confirm with other peers and resellers whether the reseller told me the truth or not. There are many experienced resellers out there. We can ask other resellers if they know this person or not and whether he is trustworthy. After a few transactions and when we get to know more about him, we can do our transactions on credit (Interview record 20090810 - LYB).

A second explanation can be referred to as the status mechanism, which entails the role and the status of resellers themselves. Most resellers are often regarded as persons with extraordinary abilities and local elites, persons who enjoy a certain socioeconomic status and prestige. A lime boss told me that they were "persons who have had successful businesses in local communities and who possess great prestige-most local people know of them". In other words, it would be difficult for a person who lacks such socioeconomic status or reputation to be qualified for this role. Therefore, these credentials could rule out those speculators without sufficient socioeconomic resources or those without a good reputation.

Resellers typically are those who enjoy prestige among the locals, and the client would not be worried if a reseller might play tricks-after all, he is from the locale. If the client received lime of poor quality, he could go and argue with the reseller. Things naturally become established this way, and the reseller thus has a special role (Interview record 20090808 - GWS).

Therefore, the two mechanisms mentioned above make the reseller a group of reliable and trustworthy businessmen. However, where does the supplier gain their confidence in the reputation of the reseller? I asked many lime bosses the following question: "For those resellers whom you don't have knowledge about or only have little knowledge about, why do you still sell them lime on credit?" ${ }^{4}$ Most of them gave it a thorough thought before answering this question, but they still could not identify a specific cause, only putting it down to something elusive like "I think he is trustworthy so I just trust him", "I know it from his look", or "I don't know exactly and I can't tell". After many interviews, I found that these seemingly irrational behaviors were actually the result of their years of experiences doing business and learning lessons-a product of their own personal histories. For instance, those who are always doubtful about every business partner and who would not give up even the tiniest profit, in the end, might lose vast opportunities within the market.

It is accurate to say that those lime bosses, who had years of experience in the lime industry, have learned to internalize the historical lessons from the industry and their own practices. Thus it entails a certain historical legitimacy with regard to their seemingly irrational behavior-making credit-based transactions with resellers even when they had little knowledge about them. In fact, their trust in the reseller did not come from the air-it involves a certain practical sense and social legitimacy. For instance, if the reseller offered to pay immediately during the first transaction, the lime 
bosses might, on the contrary, regard it as a warning signal that he should be more cautious with this transaction. One of the lime bosses, who had been in the business for almost 30 years, revealed his "reasoning" for this.

The intuition I told you about is based on our years of experience in the industry. After all these years, we have seen people of different sorts, and no matter what kind of problem-be it setback or failure, we have gone through it. It is possible to develop a basic (and correct) judgment about which type of person is trustworthy and which type you should be cautious about when making transactions with him. For those who pay immediately at the very beginning, you should not trust him too easily. Because some of the reseller might, in fact, come to you with their tricks ("dailongzi", literally carrying a cage). He starts to be very generous with the payment when he first purchases lime. When he has your trust, he will start to delay his payment. Later, he might owe you a large sum of money and stop the business, or he might even run away with your money and there is no way you can find him. We have met people like these before. In general, those who run a larger business tend to delay their payments longer and often owe more debts. Because he runs a larger business, there are many people who owe him money, and we are aware of this. Even he has some extra cash, he would not pay you immediately. He will use our money to expand his own business and to invest. Often those who have a smaller business, or those who have just entered the business for less than 3 or 5 years, will be able to pay in full (Interview record 20090314 - LYX).

Some scholars have argued that the mutual, implicit trust serves as a non-contractual base of every economic contract (Preda, 2009:10). As for the trust between the supplier and the reseller, I prefer to regard it as an internal component of the economic contract. And the trust that the suppliers developed towards the reseller as a group also made it possible for a reseller to gain trust as an individual from a supplier at the very beginning of the transaction. As a result, the two parties can benefit from their transactions based on credit but with a low level of risk. Though I asked each of the lime bosses during the interview whether a reseller had deceived them themselves or their peers, the "story" never came up in our conversation. Only one of them mentioned an unexpected risk associated with the credit-based transaction, and he attributed it to an unexpected accident, not an intentional fraud-as the reseller lost all his assets and property because of gambling debts and thus was not able to pay back the rest of his debt.

\section{Effects of accidental factors}

There were also a number of accidental factors at play during the transformation of business ethics in Hui Town. After experiencing a series of failures and frauds, some lime bosses started to reflect on the role that they played in. In the meanwhile, the lesson out of the story of the cement industry in Hui Town in the mid-1990s catalyzed collective change among lime owners in terms of their business ethics. The cement industry used to be a traditionally well-developed business in Hui Town. However, at the beginning of the 1990s, cement factories in Hui Town received serious sanctions from outside, as many of them labeled poor quality cement as high quality. Later on, even after significant improvements in their production and product quality, the cement factories in Hui Town still faced great difficulties in selling their products-simply because their reputation had collapsed in the cement industry due to their misconduct. To solve this crisis, they changed their strategies and sold their products using a brand name borrowed from other cement suppliers. 
This incident exerted a deep impact on stakeholders within the cement industry in Hui Town and had a widespread influence. Not surprisingly, this reputation crisis also struck a chord among the business owners in the lime industry, which potentially paved the way for the collective change in business ethics among lime bosses. As a consequence, the opportunist strategies they previously used were doubted by many, and those strategies that were previously deemed as coming from a "dumb head" started to gain more sense and popularity-for instance, an old saying that "qiaozha buru zhuocheng (dumb honesty is way better than a smart trick)" has become increasingly accepted.

\section{Summary and discussions}

During the "free" market stage, there were few social bonds between two parties engaged in a transaction, and both parties adopted various opportunist strategies to support their own interests. The suppliers, as "atomized" individuals, acted on purely instrumental rationality, valuing profits over justice and pursuing personal interests regardless of the interests of others or of the industry as a whole. One consequence of this was a kind of collective irrationality and broken order in the lime market, and this ultimately led to a market decline that was harmful to all players. As a result, the supplier did not trust the buyer and was only willing to make cash transactions, and when the customer came to him, the supplier sought every opportunity to take advantage of the customer. In turn, the buyer took advantage of the supplier when the lime was delivered to his door-either forcing the supplier to sell at a lower price or request a purchase on credit, and thus the failure of transaction became a common occurrence.

During the stage of "unfree" market, the change in market structure initiated a transformation in the mode of transactions, and the emergence of resellers enhanced the stability of continuing market transactions. Along with the crisis that struck the cement industry in Hui Town, there appeared an opportunity structure for lime businessmen to reflect on their own business practices and learn to adopt a new type of business ethics. This new business ethics was born out of the economic practices of the reseller, the lime business owners and the interactions between the two groups. Those business owners started to recognize the importance of trustworthiness, not only for the success of their own business but also for the well-being of the whole industry, and they learned to establish a good reputation, the process of which reflects their adaptation to a transforming market economy. In fact, their economic practices during the second stage embodied a combination of instrumental rationality and value rationality in the Weberian sense and facilitated the formation of a new type of business ethics. This new ethics served to regulate the business conduct of the two parties involved in the transaction, promoting expectations for long-term cooperation, preventing moral hazards and misconduct, thus reducing risk and uncertainty about transactions. Therefore, despite the fact that social and institutional conditions determine market structure and maintain market order (Zafirovski, 2003), the existence of these conditions itself is conditioned on other premises.

The reseller-supplier relationship became an effective structure for embedded transactions-a kind of structure that might not necessarily be efficient in an economic sense. Accordingly, the process of marketization might not necessarily be associated with depersonalization or socially disembeddedness of market transaction behaviors; on 
the contrary, the social context in which transactions are embedded may promote market development. The underlying cause for this is due to the embeddedness of the personal relationships to a shared business ethics that values social virtues; and in contrast, market development might be hindered if it was devoid of social bonds and thus bearing more resemblance to a "free" market form. In the new stage, lime transactions were based on secondary clientelist networks, the existence of which was further conditioned by social virtues such as trustworthiness and justice. In other words, the transaction was embedded in secondary clientelist networks, and the latter was embedded to a new type of business ethics. This new business ethics served as an indispensable coupling mechanism during the causal connection between a set of factors-such as relationship networks and expectations for repeated transactions, and a new market order within the lime industry in Hui Town, and it became solidified and reinforced during the production and reproduction of the secondary clientelist networks.

If seen separately, the emergence of this new transaction mode contributed to market prosperity, and the new business ethics also revitalized the market. However, the two cannot be partitioned in this way-in fact, it is the dynamic process of the two interacting with and reinforcing each other, as well as their inter-embeddedness (along with the legitimacy generated for each other), that remains key to market development. Thus the underlying mechanism for establishing a new market order and developing an "unfree" market involves a coupling induction that results from the interaction between structural embeddedness (the secondary clientelist network) and cultural embeddedness (business ethics) and their mutual reinforcement.

Additionally, this article showed that the transaction mode embedded in the secondary clientelist networks was born out of some particular institutional setting, which casts doubt on the traditional cultural determinist argument-that networks of relationships (guanxi) remain an internal component of Chinese culture and philosophy, and they can be seen as a psychological and cultural phenomenon that has its root in the peculiar mentality of the Chinese (Redding, 1990; King, 2002; Gold et al., 2002). This explanation slides into self-confirming circular reasoning-the businessman regards the relationship network as the key to success and thus establishes his own network of relationships, and he indeed reaps benefits from his network. This article found that there was a structural cause for the establishment of a new business ethics; further, the suppliers' dependence on the network of relationships was the consequence of the institutional environment of the market. Though a mark of Chinese culture can be observed from the way in which the lime suppliers manage and maintain their own networks of relationships, it does not necessarily suggest a particular social psychological foundation for the emergence and the operation of the relationship between suppliers and the reseller.

It is not difficult to figure out that suppliers' business ethics and strategies in the former stage actually exacerbated the market situations, while the establishment of a stable market order in the latter stage might not be have developed without their cognitive reflection and their individual choices in accordance with the collective rationality of the market. Accordingly, it was through the embedding of economic practices within a market culture compatible with social virtues that suppliers were able to reduce market transaction risks and uncertainties, and by establishing a new business ethics within the new market structure, the lime market has prospered. Though the 
economic outcomes of the market as a whole might depend on the macro-economic environment and the meso-level characteristics of the industry, the transformation of the market indicates that it is also important to consider businessmen's judgments and evaluation of different meaning systems and social rules based on the market circumstances that surround him, and the formation of a collective rationality of the market based on this evaluation. This type of embeddedness in a transitional market economy, as a precondition for market development, using Jens Beckert's words, "relies on increasingly more reflexively gained self-civilization" (Beckert, 2002:294).

\section{Endnotes}

${ }^{1}$ This article follows Scott's (1972:92) definition of the "patron-client relationship": "an exchange relationship between roles" that can be defined as "a special case of dyadic (twoperson) ties involving a largely instrumental friendship in which an individual of higher socioeconomic status (patron) uses his own influence and resources to provide protection or benefits, or both, for a person of lower status (client) who, for his part, reciprocates by offering general support and assistance, including personal services, to the patron."

${ }^{2}$ Here "power" takes on the meaning of the power based on a "unilateral dependence" as defined by Blau (2008:179 [1964:118]). Though resellers also relied on business owners to earn profits, they had a wider range of choices (e.g., find another local producer or even a non-local producer). In addition, the competition among local producers was extremely fierce. Thus, we have sufficient reason to believe that producers had unilateral dependence on the reseller.

${ }^{3}$ There exists an inseparable and sophisticated association between the exchange of favors, with the underlying moral principles and economic transactions within the market. Wang (2005) has discussed in depth the economic significance of moral practices, and he has pointed out that an intimate and long-lasting social relationship itself possesses economic value, as it can bring some expected revenues when individuals embed themselves into such relationship and perform their moral obligations.

${ }^{4}$ This scenario was also quite common. From the perspective of the reseller, it indicates that their reputation and trustworthiness gained among the supplier entails a group-level phenomenon that goes beyond the boundaries of personal trust, and thus an individual reseller is still able to benefit from the group's reputation.

\footnotetext{
Acknowledgements

I am indebted to Dian Yang, Peng Lv, Dandan Zheng, and Youcai Tang for valuable comments and suggestions on the earlier version of this article, some of which have been incorporated into it. And I gratefully acknowledge the support of the Foundation for the Author of National Excellent Doctoral Dissertation of PR China (grant number 201306), the Fok Ying-Tong Education for Young Teachers in the Higher Education Institutions of China (grant number 141089) and the Key Research Base of Humanities and Social Sciences of the Ministry of Education of PR China (grant number 15JJD840006).
}

Competing interests

The author declares that he has no competing interests.

Received: 12 August 2016 Accepted: 27 September 2016

Published online: 06 October 2016

References

Abolafia, Mitchel (ed.). 2005. Markets. Massachusetts: Edward Elgar Publishing Inc.

Beckert, Jens. 2002. Beyond the market: the social foundations of economic efficiency. Princeton: Princeton University Press. Blau, Peter. 2008 [1964]. Exchange and Power in Social Life, Trans. Guowu Li. Beijing: Shang Wu Yin Shu Guan. in Chinese. Burt, Ronald S. 1992. Structural hole: the social structure of competition. Cambridge: Harvard University Press.

Chan, Kwok Bun. 2000. Chinese business networks: state, economy and culture. Singapore: Pearson Education Asia Pte. Ltd. Chan, Cheris Shu-ching. 2009a. Invigorating the content in social embeddedness: ethnography of life insurance transactions in China. American Journal of Sociology. 115(3): 712-54. 
Chan, Cheris Shu-ching. 2009b. Creating a market in the presence of cultural resistance: the case of life insurance in China. Theory and Society 38: 271-305.

Dickson, Bruce J. 2008. Wealth into power: the communist party's embrace of China's private sector. Cambridge: Cambridge University Press.

Fan, Ying. 2002. Guanxi's consequences: personal gains at social cost. Journal of Business Ethics 38(4): 371-80. Fei, Xiaotong. 1998. Earthbound China. Beijing: Peking University Press. in Chinese.

Ferraro, Emilia. 2006. Culture and economy: the case of the milk market in the northern Andes of Ecuador. Ethnology 45(1): 25-39. Fligstein, Neil. 2008 [2002]. The Architecture of Market: An Economic Sociology of Twenty-First-Century Capitalist Societies, Trans. Zhihong Zhen. Shanghai: Shanghai People's Publishing Press. in Chinese.

Fu, Ping. 2009. Embeddedness: divergence and controversy. Sociological Studies 5: 141-164.

Fu, Ping. 2010. Towards an integrative paradigm of sociology of markets. Sociological Studies 2: 211-225.

Gold, Thomas, Doug Guthrie, and David L. Wank (eds.). 2002. Social connections in China: institutions, culture, and the changing nature of guanxi. Cambridge: Cambridge University Press.

Granovetter, Mark. 1985. Economic action and social structure: the problem of embeddedness. American Journal of Sociology 91(3): 481-510.

Hamilton, Gary G. 2006. Commerce and capitalism in Chinese societies. London: Routledge.

Keister, Lisa A. 2001. Exchange structures in transition: lending and trade relations in Chinese business groups. American Sociological Review 66(3): 336-60.

Kettering, Sharon. 1988. The historical development of political clientelism. The Journal of Interdisciplinary History 18(3): 419-47.

King, Ambrose Yeo-chi. 2002. The construction of Guanxi and network, Selected Work of Ambrose Yeo-chi King. Shanghai: Shanghai Education Press. in Chinese.

Kipnis, Andrew B. 1997. Producing Guanxi: sentiment, self, and subculture in a north china village. Durham: Duke University Press.

Lee, Khan-Pyo. 2007. Clans for markets: the social organization of inter-firm trading relations in China's automobile industry. The China Quarterly 192: 876-97.

Li, John Shuhe. 2003. Relation-based versus rule-based governance: an explanation of the east Asian miracle and Asian crisis. Review of International Economics 11(4): 651-73.

Liang, Shuming. 2005. The substance of Chinese culture. Shanghai: Shanghai People's Publishing Press. in Chinese. Lu, Ming, and Hui Pan. 2009. Bond between governments and enterprises. Beijing: Peking University Press. in Chinese. Luo, Yadong. 2007. Guanxi and business, 2nd ed. New Jersey: World Scientific.

Nee, Victor. 1992. Organizational dynamics of market transition: hybrid forms, property rights, and mixed economy in China. Administrative Science Quarterly 37(1): 1-27.

North, Douglass C. 1994 [1990]. Institutions, Institutional Change, and Economic Performance, Trans. Shouying Liu. Shanghai: Joint Publishing Company. in Chinese.

North Douglass, C. 1992[1981]. Structure and Change in Economic History, Trans. Yiping Li. Bejing: The Commercial Press. in Chinese.

Odgaard, Ole. 1992. Private enterprises in rural China: impact on agriculture and social stratification. Avebury: Aldershot, Hants, and England.

Oi, Jean Chun. 1989. State and peasant in contemporary China: the political economy of village government. Oxford: University of California Press.

Oi, Jean Chun. 1999. Rural China takes off: institutional foundations of economic reform. Berkeley: University of California Press.

Preda, Alex. 2009. Information, knowledge, and economic life: an introduction to the sociology of markets. Oxford: Oxford University Press.

Redding, S. Gordon. 1990. The spirit of Chinese capitalism. Berlin: W. de Gruyter.

Scott, James C. 1972. Patron-client politics and political change in southeast Asia. The American Political Science Review 66(1): 91-113.

Shirk, Susan L. 1993. The political logic of economic reform in China. Berkeley: University of California Press.

Slater, Don, and Fran Tonkiss. 2001. Market society: markets and modern social theory. Cambridge: Polity Press.

Su, Chenting, and James E. Littlefield. 2001. Entering Guanxi: a business ethical dilemma in mainland China? Journal of Business Ethics 33(3): 199-210.

Swidler, Ann. 1986. Culture in action: symbols and strategies. American Sociological Review 51(2): 273-86.

Tang, Li. 2003. The generation of networks: an underground economical group as a critical case. Sociological Studies 5: 95-106. Tang, Youcai, and Fu, Ping. 2008. Mechanisms determining social trust in transitional China. Zhejiang Social Sciences 11: 59-67.

Wang, Hejian. 2005. Durkheim revisited: the social construction of morality in modern economy. Sociological Studies 1: 149-167.

Wank, David L. 1995. Private business, bureaucracy, and political alliance in a Chinese city. The Australian Journal of Chinese Affairs 33(January): 55-71.

Wank, David L. 1996. The institutional process of market clientelism: Guanxi and private business in a South China City. The China Quarterly 147: 820-38.

Wank, David L. 1999. Producing property rights. In Property rights and economic reform in China, ed. Jean C. Oi and A.G. Walder. Stanford: Stanford University Press.

Warner, R. Stephen. 1978. Toward a redefinition of action theory: paying the cognitive element its due. American Journal of Sociology 83(6): 1317-49.

Weber, Max. 2006[1927]. General Economic History, Trans. Zengyi Yao. Shanghai: Joint Publishing Company. in Chinese.

Weber, Max. 2006[1925]. Economy and Society, Trans. Rongyuan Lin. Beijing: The Commercial Press. in Chinese.

Weber, Max. 2010 [1904]. Protestant Ethics and The Spirit of Capitalism, Trans. Guoxun Su. Beijing: Social Sciences Academic Press. in Chinese.

Whyte, Martin King. 2009. Paradoxes of China's economic boom. Annual Review of Sociology 35(1): 371-92.

Zafirovski, Milan. 2003. Market and society: two theoretical frameworks. Westport, Conn.: Praeger.

Zelizer, Viviana A. 1978. Human values and the market: the case of life insurance and death in $19^{\text {th }}$-century America. American Journal of Sociology 84(3): 591-610.

Zelizer, Viviana A. 1985. Pricing the priceless child: the changing social value of children. New York: Basic Books.

Zhang, Wanli. 1996. Non-institutional factors and obtaining status. Sociological Studies 1: 64-73.

Zou, Dang. 2002. The social scientification of political studies. In Reinterpretation of Chinese revolutions, Dang Zou. Hong Kong: Oxford University Press. 